\title{
Ántrax cutáneo, último brote diagnosticado en Chile
}

\author{
Sebastián Arellano, Daniela Soto, Ma. Beatriz Reeves, \\ Francisco Chávez, Rodrigo Loubies y Andrés Ojeda
}

\section{Cutaneous anthrax, the last outbreak diagnosed in Chile}

Anthrax is a zoonosis caused by a spore-forming bacterium, called Bacillus anthracis. Naturally it is of global distribution, with a predilection in agricultural zones with few norms of public veterinary health. Human contagion occurs through the consumption of diseased animal's meat or through a doorway into the skin or through the spores inhalation of products derived from the affected animal (wool, leather, bones). The most frequent infection in humans occurs in the skin, followed by the gastrointestinal tract and lungs. We present the last outbreak of cutaneous anthrax diagnosed in Chile with a description of the first two clinical cases of the outbreak. Control disease is based on prevention, hence the importance of surveillance in detecting cases and outbreaks.

Key words: Anthrax; cutaneous anthrax; zoonoses.

Palabras clave: Ántrax; ántrax cutáneo; zoonosis.

\section{Introducción}

$\mathrm{E}$ lántrax, carbunco o enfermedad de los cardadores de lana, es una enfermedad zoonótica causada por Bacillus anthracis, perteneciente a la familia Bacillaceae. Es un bacilo grampositivo, anaerobio facultativo y capsulado. Es esporogénico en aerobiosis. Tiene un tamaño de 1-3 x 3-10 $\mu \mathrm{m}$ y las esporas miden 2-5 $\mu \mathrm{m}$ de diámetro, las que son capaces de permanecer por décadas en el medio ambiente ${ }^{1}$. En estado vegetativo, la bacteria tiene una pobre sobrevida fuera de su hospedero humano o animal.

Los hospederos habituales de $B$. anthracis son herbívoros (vacunos, ovejas, cabras, caballos) y el cerdo como animal omnívoro. En su gran mayoría, los casos de carbunco son reportados en regiones con escasos programas de salud veterinarios, tales como Centro y Sudamérica, Medio Oriente, África, Caribe y Sudeste de Europa.

En Chile, la última información disponible del Ministerio de Salud detalla que entre los años 1990 y 2000 se produjeron 224 casos, con una tendencia a la baja. En el mismo período hubo nueve fallecidos, de los cuales dos fueron por ántrax pulmonar, uno por septicemia y en los otros casos no hubo causa precisada de muerte ${ }^{4}$. La enfermedad se presentó en los Servicios de Salud de Ñuble, Bío-Bío, Osorno, Aysén, Coquimbo, Araucanía y Maule. La mayor frecuencia de casos fue en estas dos últimas regiones.

Los animales adquieren la infección mediante la inhalación o ingesta de esporas provenientes del pasto, agua u otros alimentos contaminados. El ser humano es un hospedero accidental, que en forma excepcional puede transmitir la infección a otra persona. Su contagio se produce por el consumo de esporas presentes en carnes crudas o mal cocidas de animales enfermos, mediante la inhalación de esporas durante la manipulación de productos animales como lana, hueso, cuero, pelo ${ }^{1,3,4}, \mathrm{o}$ a través de una puerta de acceso de la piel de personas que han estado en contacto con animales infectados o con sus derivados. Últimamente, en el norte de Europa se ha descrito su transmisión por vía intravenosa en consumidores de heroína.

La infección se inicia al introducirse las esporas al organismo ya sea por vía cutánea, intestinal o respiratoria. La germinación de las formas vegetativas ocurre localmente o en los ganglios linfáticos regionales mediante el transporte vía macrófagos a traves del sistema linfático. Las formas vegetantes comienzan a esporular, tardando entre 2 a 5 días en la forma cutáneo-intestinal y en la forma respiratoria puede tardar hasta 60 días en germinar. Posteriormente ocurre la diseminación sanguínea, y multiplicación extracelular ${ }^{1}$, lo que puede dar como resultado una bacteriemia, meningitis, sepsis y, en algunos casos, shock séptico y muerte.

Los factores de virulencia de $B$. anthracis están dados por el antígeno protector, que en combinación al factor edema y factor letal, da origen a toxina del edema y toxina letal respectivamente. El antígeno protector es capaz de unirse a un receptor de toxina del ántrax ubicado en la superficie de las células, permitiendo el paso vía endocitosis del complejo antígeno-factor. Una vez ingresados a la célula, ocurre la translocación de los factores edema y letal, afectando las funciones de proliferación celular y la modulación del sistema inmune ${ }^{5}$. La toxina edematizante junto con la toxina letal actúan para causar trombosis vascular, necrosis tisular y edema ${ }^{1,4}$.
Hospital El Pino, Santiago. Servicio de Dermatología (FCh, $\mathrm{RL})$. Universidad de Santiago de Chile. Programa de Especialidad en Dermatología (SA, DS). Universidad Diego Portales, Hospital El Pino, Santiago (MBR).

Servicio de Salud Nuble. CESFAM Pemuco (AO).

Sin conflicto de interés. No existe fuente de financiamiento para la realización de esta publicación.

Recibido: 27 de julio de 2017 Aceptado: 12 de diciembre de 2017

Correspondencia a: M. Beatriz Reeves beatriz.reeves@hotmail.com 
Figura 1. Caso 1, dedo índice. A: placa livedoide con borde necrótico incipiente y edema perilesional. B: úlcera con centro necrótico deprimido. C: hipopigmentación residual de la lesión.
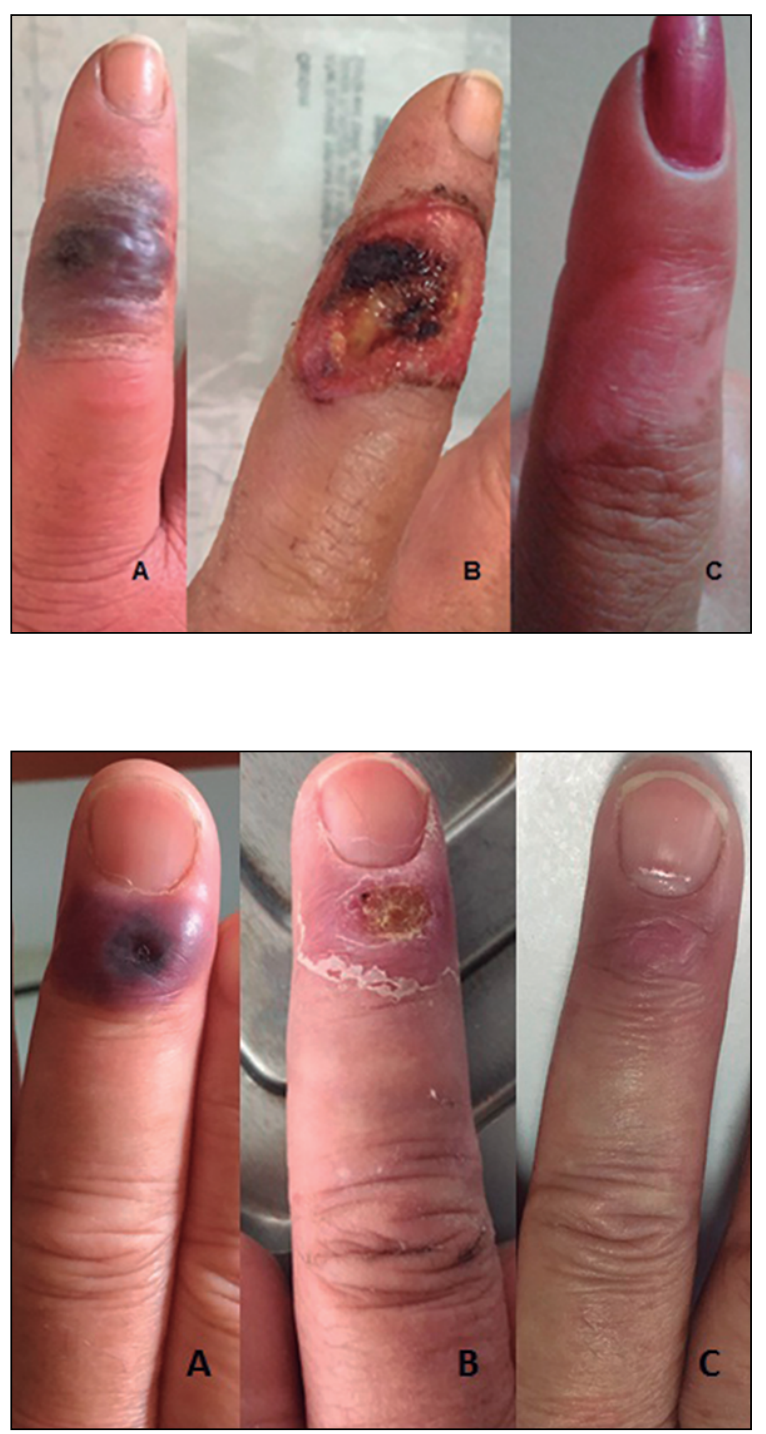

El ántrax cutáneo es el más frecuente dentro de las diversas presentaciones, representando cerca de $95 \%$ de los $\operatorname{casos}^{4,6}$. La tasa de letalidad es de $20 \%$ en los pacientes no tratados, disminuyendo a $1 \%$ al recibir la antibioticoterapia adecuada. En el caso del ántrax gastrointestinal las cifras fluctúan entre $25-75 \%$ y el ántrax respiratorio puede alcanzar hasta $100 \%$ de letalidad en caso de no recibir tratamiento ${ }^{1,6}$.

La lesión típica del ántrax cutáneo se caracteriza por una mácula o pápula pruriginosa que evoluciona en uno a dos días a una vesícula y posteriormente, entre los dos y seis días, aparece una úlcera necrótica no dolorosa con una costra, circundada por tejido edematoso ${ }^{7}$. Los sitios de infección más comunes en la piel son las manos (68\%), antebrazos $(12 \%)$, párpados $(7 \%)$ y cuello $(3 \%)^{8}$.

\section{Casos clínicos}

Mujer de 44 años, sin antecedentes mórbidos, consultó en una posta rural por una lesión, de cuatro días de evolución, en la falange media del dedo índice de la mano derecha. En un inicio la paciente refirió la aparición de una pápula pruriginosa única. $\mathrm{Al}$ momento de la consulta se encontraba afebril, en buen estado general, con la presencia de una lesión máculo-papular violácea descamativa, con edema perilesional. En los días siguientes evolucionó a una úlcera con centro necrótico, dolorosa (Figuras 1a y 1b), sin síntomas sistémicos. Al día siguiente consultó otra mujer de 62 años, previamente sana, por un cuadro de tres días de evolución, de una mácula pruriginosa en la falange distal del dedo medio de la mano derecha. $\mathrm{Al}$ examen físico presentaba una placa negruzca deprimida, rodeada de un halo violáceo. Posteriormente evolucionó a una úlcera no dolorosa (Figuras 2a y 2b). Se recibió el antecedente que ambas pacientes eran hermanas y que habían manipulado y consumido carne de origen equino, que había sido faenado hacía siete días en forma artesanal, en condiciones sanitarias deficientes. Se contactó a la SEREMI de Salud por sospecha de carbunco. Ambas pacientes fueron internadas y tratadas en forma empírica con penicilina $\mathrm{G}$ sódica intravenosa.

Funcionarios de la autoridad sanitaria tomaron muestras directamente desde las lesiones de las pacientes y en el terreno de faenamiento del equino, resultando ambas positivas para $B$. anthracis. Se realizó el protocolo de profilaxis antibacteriana a las personas que habían consumido la carne y se aplicaron medidas de control epidemiológico en la región. Las pacientes evolucionaron favorablemente, con cambios en la pigmentación de los dedos afectados, sin cicatrices residuales (Figuras 2c y $3 \mathrm{c}$ ). Los casos expuestos al consumo y/o manipulación de la carne infectada se elevaron a 34. Finalmente, los casos confirmados de carbunco cutáneo ascendieron a cuatro, todos con muy buena evolución.

\section{Discusión}

Cabe destacar que ambos casos presentados se manifestaron en la mano dominante de ambas mujeres, con la que seguramente mantuvieron un mayor contacto con el animal muerto durante su faenamiento. Otro punto a mencionar, es la presencia de una úlcera dolorosa en la primera paciente, característica que difiere de la literatura especializada, donde se describe clásicamente como una lesión no dolorosa. Probablemente, la presencia de edema y/o sobreinfección bacteriana pudieron ser los gatillantes del dolor.

Dentro de los principales diagnósticos diferenciales a considerar en las lesiones cutáneas descritas, destacan 
el ectima contagioso (virus orf), el ectima gangrenoso causado por Pseudomonas aeruginosa, loxoscelismo cutáneo, tularemia úlceroglandular (Franciscella tularensis), el carbúnculo estafilocóccico (lesión de evolución más prolongada, dolorosa y sin producción de escaras), peste bubónica (Yersinia pestis), y la fiebre por mordedura de rata con Streptobacillus moniliformis y Spirillum como agentes causales.

El diagnóstico de ántrax se realiza mediante la detección de $B$. anthracis en la piel, secreciones respiratorias, LCR y/o sangre. Frente a la sospecha de ántrax cutáneo se recomienda extraer una muestra para tinción de Gram, cultivo (rendimiento de $60-65 \%{ }^{3}$ ), biopsia para estudio histopatológico y hemocultivos en los cuadros sistémicos. De ser necesario, se puede proceder a la detección de anticuerpos mediante técnicas más precisas como inmunohistoquímica, inmunofluorescencia y reacción de polimerasa en cadena.

Penicilina $\mathrm{G}$ es el antimicrobiano de elección en casos de ántrax cutáneo, por tres a siete días ${ }^{9}$. Las quinolonas (ciprofloxacina) y doxiciclina también son una opción para el tratamiento del ántrax cutáneo en adultos y como quimioprofilaxis en personas expuestas por inhalación o ingesta de esporas provenientes de animales muertos o sus productos ${ }^{8,9}$.
Agradecimientos. Al Servicio de Dermatología y Venerología del Hospital El Pino y al Servicio de Salud Ñuble por facilitar los casos expuestos en este manuscrito.

\section{Resumen}

El ántrax, es una zoonosis causada por una bacteria generadora de esporas, llamada Bacillus anthracis. En forma natural tiene una distribución global, con una predilección en zonas agrícolas con pocas normativas de sanidad pública veterinaria. El contagio humano ocurre por el consumo de carnes de animales enfermos, por contacto a través de una puerta de entrada en la piel o por la inhalación de esporas de productos derivados del animal afectado (lana, cuero, huesos). La infección en los seres humanos compromete con mayor frecuencia la piel, seguido por el tracto gastrointestinal y los pulmones. El control de la enfermedad se basa en la prevención, de allí la importancia de la vigilancia en la detección de casos y brotes. Presentamos el último brote de ántrax cutáneo diagnosticado en Chile con descripción de dos primeros casos clínicos del brote.

\section{Referencias bibliográficas}

1.- Valdespino-Gómez J L, García-García M de L. El A, B, C, sobre ántrax, para personal de salud. Salud Pública Méx 2001; 43: 604-13.

2.- Huang Y, Du Y, Wang Y, Wang N, Bai J, Chen $\mathrm{H}$, et al. An outbreak of cutaneous anthrax in Yunnan, China. Emerg Microbes Infect 2016; 5: e64. doi: 10.1038/emi.2016.65.

3.- Deb S, Samanta A B. A case of cutaneous anthrax presenting with classical lesions. Int J Dermatol 2015; 54: e539-41. doi: 10.1111/ ijd.13090.

4.- Perret C, Maggi L, Pavletic C, Vergara R,
Abarca K, Dabanch J, et al. Ántrax (Carbunco). Rev Chilena Infectol 2001; 18: 291-9.

5.- Bower WA, Hendricks K, Pillai S, Guarnizo J, Meaney-Delman D. Clinical Framework and Medical Countermeasure Use During an Anthrax Mass-Casualty Incident. MMWR Recomm Rep. 2015 Dec 4; 64 (4): 1-22. doi:10.15585/mmwr.rr6404a1.

6.- Welkos S, Bozue J, Twenhafel N, Cote C. Animal models for the pathogenesis, treatment, and prevention of infection by Bacillus anthracis. Microbiol Spectr 2015; 3: TBS0001-2012. doi: 10.1128/microbiolspec.TBS0001-2012.
7.- Chatterjee K, Chaudhuri A, Chatterjee G. Charbon: a classical presentation. Int $\mathrm{J}$ Dermatol 2014: 53: 879-81. doi: 10.1111/ ijd.12446.

8.- Gilliland G, Starks V, Vrcek I, Gilliland C. Periorbital cellulitis due to cutaneous anthrax. Int Ophthalmol 2015; 35: 843-5. doi: $10.1007 /$ s10792-015-0057-7.

9.- World Health Organization. Anthrax in humans and animals. 4th ed. Geneva, Switzerland. WHO Library Cataloguing-inPublication Data; 2008. http://apps.who.int/iris/ bitstream/10665/97503/1/9789241547536_eng. pdf 